\title{
O Mercosul e a construção de uma política ambiental para os países do Cone Sul
}

\author{
Aninho Mucundramo Irachande* \\ Lucimar Batista de Almeida** \\ Marilene Maria Augusto Vieira***
}

\section{Resumo}

Desde 1991, quando Argentina, Brasil, Paraguai e Uruguai acordaram a criação do Mercosul, até a presente data, tem havido relativo avanço no processo de integração comercial entre esses países, porém verifica-se pouco progresso no que diz respeito à consideração das questões ambientais nesse fórum de discussão. O presente artigo busca analisar o tratamento que a questão ambiental no Mercosul vem tendo nos vários instrumentos legais institucionalizados, mostrando as diferentes tentativas na adoção de providências no sentido de harmonizar a legislação ambiental, e as razões para o estabelecimento de uma política comum de proteção ambiental dentro de um processo de integração regional, sem que isso signifique a unificação das políticas ambientais dos diferentes países membros.

Palavras chave: Tratado de Assunção, Mercosul, questão ambiental, integração comercial, Protocolo Ouro Preto.

* Doutor em Política e Gestão Ambiental pelo Centro de Desenvolvimento Sustentável/Universidade de Brasília (CDS/UnB). Coordenador do Curso de Relações Internacionais do Instituto de Educação Superior de Brasília (IESB), Brasília-DF. Endereço eletrônico:aninho@iesb.br.

粠 Doutoranda em Desenvolvimento Sustentável do Centro de Desenvolvimento Sustentável/Universidade de Brasília (CDS/UnB), Analista em Ciência e Tecnologia (C\&T) do Conselho Nacional de Desenvolvimento Científico e Tecnológico (CNPq/MCT), Brasília-DF. Endereço eletrônico: lalmeida@cnpq.br.

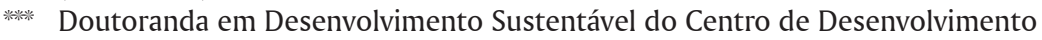
Sustentável/Universidade de Brasília (CDS/UnB). Analista em Ciência e Tecnologia (C\&T) da Coordenação de Aperfeiçoamento de Pessoal de Nível Superior (Capes/ MEC), Brasília-DF. Endereço eletrônico: marileneaugusto@terra.com.br. 


\section{Introdução}

Em 26 de março de 1991 foi subscrito o Tratado de Assunção

Eentre a Argentina, Brasil, Paraguai e Uruguai, que estabeleceu a constituição do Mercado Comum do Sul que viria a ser concretizado em 1994. Este Tratado, bem como os instrumentos legais posteriores firmados entre os países da região, materializou a antiga aspiração de seus povos, refletindo os crescentes entendimentos políticos em âmbito regional, a densidade dos vínculos econômicos e comerciais e as facilidades de comunicação propiciadas pela infraestrutura de transporte dos quatro países e pela natural integração dos seus territórios, das condições geográficas e de passado comum.

A criação do Mercosul, objetivo definido pelo Tratado de Assunção e reafirmado pelo Protocolo Ouro Preto não foi, portanto, uma ação diplomática isolada, muito menos sui generis, mas sim o resultado de um longo processo de aproximação e convivência entre os países da região iniciado na década anterior.

O Tratado de Assunção incorporou boa parte dos instrumentos em vigor entre Brasil e Argentina desde o final de 1990 no Acordo de Complementação Econômica nํ․14 (ACE-14), subscrito entre ambos os países no âmbito da Associação Latinoamericana de Integração (ALADI). Nele abandonam-se os critérios seletivos de abertura de mercado e passa-se a um processo de desagravação progressiva, linear e automática. Além disso, promove-se uma gradativa exposição dos setores considerados "sensíveis" pela eliminação progressiva das chamadas "listas de exceções". Finalmente, a ênfase da ação governamental desloca-se do monitoramento da expansão e do equilíbrio do intercâmbio (realizada no passado por meio de mecanismos compensatórios e de negociações setoriais ou por produtos), para as tarefas de harmonização de instrumentos de políticas comercial, setorial e macroeconômica.

Isso foi possível graças aos programas econômicos adotados pelos governos na região, favoráveis à abertura econômica, à concorrência ampliada, ao aumento da eficiência, à modernização e à inserção mais competitiva das economias latinoamericanas no mercado mundial. O Mercosul visava, assim, primordialmente, somar competências e maximizar vantagens comparativas em escala 
regional. Nessa perspectiva, encarava os mercados de seus integrantes como um espaço ampliado, capaz de assegurar economias de escala e de contornar as limitações impostas por demandas internas conjunturalmente reprimidas. Subsidiariamente, a integração dos mercados contribuiria para refrear tendências oligopolísticas e para intensificar o debate interno sobre a necessidade de superação de gargalos estruturais das economias. Além disso, esperava-se que, no futuro, os sócios do Mercosul viessem a ratear os custos de investimentos em pesquisa e desenvolvimento, aspectos cruciais do projeto maior de modernização de suas economias.

O desafio era como operacionalizar uma maior especialização e reestruturação dos parques produtivos sem promover uma competição selvagem em alguns segmentos e sem desestabilizar setores sensíveis, em geral, no caso brasileiro, localizados na área agrícola. O projeto deveria, assim, evoluir para a formulação de mecanismos e instrumentos que transcendessem os prescritos em uma pura e simples abertura de mercados e que propiciassem condições para a reestruturação desses setores produtivos, em um esquema modernizante e dentro de regras equitativas de concorrência.

Embora o preâmbulo do Tratado de Assunção mencione a necessidade de aproveitar de forma mais eficiente os recursos disponíveis, preservar o meio ambiente, melhorar as interconexões físicas entre os países, coordenar políticas macroeconômicas e garantir a complementação dos diferentes setores da economia, tendo como princípios gradualidade, flexibilidade e equilíbrio, a construção e observância da Política Ambiental nunca ocupou lugar de destaque na política geral do Bloco.

Tendo como referência este cenário, o presente artigo busca verificar como a temática ambiental foi inserida e está sendo tratada nos principais instrumentos do bloco regional Mercosul. Conforme se perceberá ao longo deste artigo, há uma crônica tendência no Mercosul em tratar as questões ambientais em segundo plano, em relação às negociações comerciais, dando, assim, maior ênfase à competitividade internacional, pois elas ainda não repercutem, de forma incisiva, na formulação de políticas e regulamentações públicas de impacto. Vale constatar que em diferentes momentos o processo de integração do Mercosul 
tem priorizado determinadas questões em detrimento de outras pautas. Um exemplo atual, após o esfriamento dos avanços comerciais verificados nos anos 1990, pode ser observada uma maior incidência de temas sociais nos debates intra-bloco e não mais a proeminência dos assuntos econômico-comerciais que dominaram os primeiros anos de existência do acordo.

\section{Mercosul e a política ambiental comum}

O Mercosul foi concebido como um projeto de integração entre Brasil, Argentina, Uruguai e Paraguai com o objetivo de ampliar as dimensões dos mercados nacionais, condição fundamental para acelerar o desenvolvimento econômico da região e melhorar sua inserção no mercado internacional. Para alcançar esse objetivo, o preâmbulo do Tratado de Assunção menciona a necessidade de aproveitar, de forma mais eficiente, os recursos disponíveis, preservar o meio ambiente, melhorar as interconexões físicas entre os países, coordenar políticas macroeconômicas e garantir a complementação dos diferentes setores da economia, tendo como princípios gradualidade, flexibilidade e equilíbrio.

A questão ambiental começou a ser considerada no Mercosul quase um ano depois da assinatura do Tratado de Assunção. Em fevereiro de 1992, representantes dos quatro países membros reuniram-se em Canela (RS) para negociar, a partir de diagnósticos ambientais nacionais previamente realizados, uma posição comum a ser apresentada pelos países do Cone Sul na Conferência Rio-92, que se realizaria em junho, no Brasil.

O governo brasileiro argumentava que os países desenvolvidos deveriam assumir responsabilidade pela transferência de tecnologias limpas e recursos financeiros - novos e adicionais - aos países em desenvolvimento, cujas economias não poderiam arcar sozinhas com os custos da reconversão tecnológica ao desenvolvimento sustentável. A posição da Argentina, do Uruguai e do Paraguai era mais moderada em relação às obrigações dos países desenvolvidos e acabou por prevalecer no documento final da reunião - Declaração de Canela -, que praticamente não menciona compromissos para o mundo industrializado (MACIEL apud OLIVIERI, 1995). 
Ainda em 1992, em Las Lenhas, Argentina, o Grupo Mercado Comum (GMC), órgão executivo do Mercosul, decidiu criar a Reunião Especializada do Meio Ambiente (REMA), cujos objetivos principais seriam analisar a legislação vigente nos Estados-Membros e propor medidas de proteção ambiental por meio de recomendações ao GMC. A criação da REMA parecia indicar que o tema ambiental assumiria, doravante, alguma importância no contexto das negociações do processo da integração regional. No entanto, por não constituir um subgrupo de trabalho técnico oficial, a REMA funcionava como estrutura paralela aos mecanismos de tomada de decisão institucionais, o que limitava sobremaneira sua atuação e o alcance e aplicabilidade de suas recomendações.

Durante os anos de 1993 e 1994, em diversos encontros, analisaram-se as legislações nacionais em matéria ambiental e coordenou-se a ação da REMA com a dos Subgrupos de Trabalhos Técnicos (SGTs), cujas atividades poderiam ser relacionadas a temas ambientais, a saber, política industrial e tecnológica (SGT-7), política agrícola (SGT-8) e política energética (SGT-9).

Dentro do SGT de Política Industrial e Tecnológica foi criada a Comissão de Meio Ambiente (CMA-SGT-7), cujo objetivo era harmonizar a legislação ambiental dos quatro países no setor industrial, comparando as normas vigentes sobre atividades industriais e seu efetivo cumprimento e analisando as possíveis consequiências sobre a internalização de custos e o desenvolvimento sustentável. Para a Comissão, o termo harmonização não significava criar uma legislação única para todos os países, mas estabelecer critérios comuns para a adequada consideração das questões ambientais. A adoção desses critérios não deveria gerar vantagens econômicas para determinado segmento industrial de um dos países em função da aplicação nos demais integrantes do bloco, de legislações ambientais mais restritivas, que impusessem custos adicionais às empresas. Todos os acordos intergovernamentais - regionais e internacionais - dos quais cada país é signatário deveriam ser considerados, respeitando as diferenças naturais, socioculturais e político-administrativas dos quatro parceiros (ANDERSEN apud OLIVIERI, 1995).

Como resultado desse trabalho, a CMA-SGT-7 definiu objetivos e uma estratégia operativa, identificou a legislação pertinente, 
elaborou matrizes comparativas para parâmetros de qualidade e emissão de poluentes e identificou as principais assimetrias entre os países. Estudos de três segmentos industriais de poluição intensiva - química e petroquímica, papel e celulose e couro - foram encomendados, devendo considerar aspectos legais para licenciamento e funcionamento das indústrias; controle da poluição, tratamento e disposição dos efluentes; manipulação, transporte e comercialização de produtos.

O SGT-8 (Política Agrícola) analisou as legislações vigentes nos quatro países, a fim de delinear uma política regional de produção agropecuária sustentável. As principais ações recomendadas visavam promover a produção agropecuária não dependente da mera extração de recursos naturais, dando prioridade às ações preventivas para conservação, defesa e melhoria da região e observando o cumprimento, no âmbito da atividade agropecuária, das legislações vigentes sobre proteção de recursos naturais. A harmonização das legislações deveria considerar as diferentes realidades nacionais, facilitando a criação de instrumentos de captação de recursos financeiros para resolver problemas ambientais regionais, por meio de projetos de recuperação de áreas frágeis. Como conclusão desse trabalho, apresentou-se à coordenação do SGT-8 a recomendação de que o setor agropecuário adotasse as diretrizes básicas elaboradas pela REMA.

No SGT-9 (Política Energética) foi criado o Comitê de Meio Ambiente, que propôs a utilização de tecnologias limpas, o melhoramento da eficiência energética e a definição de um marco de regulamentação ambiental para o setor no âmbito do Mercosul. O Comitê também recomendou a criação de uma Comissão de Meio Ambiente, cuja tarefa seria a comparação das legislações existentes, a harmonização das políticas de gestão ambiental e a elaboração de metodologia para incorporação dos custos ambientais aos projetos energéticos. A Comissão recomendou que o GMC incluísse os seguintes itens de uma futura legislação ambiental em matéria energética: avaliação de impacto ambiental de toda nova atividade energética; planos de gestão ambiental e correspondentes medidas de prevenção e correção de efeitos danosos; gestão ambiental 
integrada de bacias; auditoria ambiental das atividades energéticas existentes; estabelecimento de padrões de qualidade de efluentes industriais líquidos, sólidos e de emissões gasosas; uso, manejo e disposição final de resíduos, especialmente os perigosos; planos de contingência para toda a atividade energética; e programas de informação comunitária (MACIEL apud OLIVIERI, 1995).

Com base nesses e outros estudos, a REMA elaborou as Diretrizes Básicas em matéria de Política Ambiental, aprovadas pela Resolução no. 10/94 do GMC. As diretrizes tinham como objetivo assegurar condições equitativas de competitividade no Mercosul, com a adoção de práticas de manejo sustentável no aproveitamento de recursos naturais, uso de tecnologias adequadas de produção, reciclagem e tratamento de resíduos, harmonização dos procedimentos legais de habilitação e acompanhamento de atividades passíveis de gerar impactos ambientais em ecossistemas compartilhados. Outros objetivos eram a criação de critérios ambientais comuns para negociação e implementação de atos internacionais com repercussões sobre o processo de integração e estímulo ao desenvolvimento de turismo regional sem prejuízo ao meio ambiente. As diretrizes constituiriam o ponto de partida para a criação de uma legislação ambiental do Mercosul.

Em junho de 1995, a realização da Primeira Reunião de Ministros do Meio Ambiente do Mercosul, em Montevidéu, marcou o crescimento do tema ambiental nas negociações do bloco comercial regional. Nessa ocasião, foram debatidos os efeitos dos custos ambientais dos processos produtivos sobre a competitividade de empresas e produtos do Mercosul no mercado internacional. Introduziu-se a discussão sobre a adoção das normas de qualidade ambiental da série ISO 14000 como fator diferenciador de competitividade para produtos originários do Mercosul. O documento final do encontro - Declaração de Taranco - recomendou a consideração dos custos ambientais, como forma de assegurar condições equânimes de proteção ambiental e competitividade aos quatro parceiros do Mercosul.

Outras recomendações da Declaração de Taranco foram: prioridades na análise de impacto ambiental do projeto Hidrovia 
Paraná - Paraguai; necessidade de eliminar assimetrias nas legislações ambientais nacionais dos sócios do Mercosul; coordenação de posições sobre diversidade biológica, mudança climática e implementação da Agenda 21 em foros internacionais; apoio ao processo de descentralização e regionalização das atividades do PNUMA e presença mais ativa nos trabalhos desse órgão e na Comissão de Desenvolvimento Sustentável da ONU.

A Declaração de Taranco recomendou, ainda, que a REMA se transformasse no Subgrupo de Trabalho de Meio Ambiente (SGT-6) que passou a funcionar a partir de 1995 , subordinado ao Grupo Mercado Comum (GMC).

Criado por resolução do GMC, no final de 1995, o SGT-6 vem discutindo uma pauta de negociação que pouco tem mudado ao longo dos anos, desde que foi estabelecida pela Resolução no. 38/95, a partir das Diretrizes da REMA. Os itens recorrentes da pauta são:

- Criação de instrumentos jurídicos conjuntos em matéria ambiental para o Mercosul;

- Análise de restrições não-alfandegárias ao comércio com justificativa ambiental;

- $\quad$ Competitividade e meio ambiente;

- Adaptação dos países às normas institucionais da série ISO 14.000;

- Instituição de Selo Verde no Mercosul;

- $\quad$ Sistema de informação ambiental;

- Temas setoriais, envolvendo subgrupos de políticas industrial, agrícola e energética.

O SGT-6, desde a sua criação em 1995, vem realizando reuniões ordinárias (a cada três meses) e extraordinárias sempre que acordado entre os parceiros. Uma verificação acurada das pautas das mais de trinta reuniões já realizadas desde sua criação mostra como os assuntos e resultados são repetitivos, recorrentes e com avanços bastante limitados. Alguns temas permanecem na pauta até a atualidade sem que se tenha de fato conseguido equacionar os propósitos 
iniciais como, por exemplo, a questão do Sistema de Informações Ambientais, Selo Verde, Emergências Ambientais, entre outros.

\section{Do Protocolo Adicional ao Acordo-Quadro}

Em razão da necessidade de um documento único que diminuísse as divergências e harmonizasse as legislações, aperfeiçoasse os níveis de qualidade ambiental e oferecesse um modelo para ordenamento jurídico, o SGT-6 tinha, como uma das tarefas prioritárias, criar um "Instrumento Jurídico de Meio Ambiente no Mercosul", que abarcasse as diretrizes básicas apontadas na resolução 10/94, do GMC. De maneira geral, essas diretrizes dizem respeito a: harmonização das legislações, aplicação do desenvolvimento sustentável no Mercosul, adoção de políticas de fiscalização das atividades causadoras de impacto ambiental, estudos e tecnologias que propiciem a diminuição da emissão de poluentes, fortalecimento das instituições garantidoras da gestão ambiental e a aplicação desses princípios na área turística (LOPES, 2002).

Em 1997, o SGT-6 elaborou o "Projeto de Decisão relativo ao Protocolo Adicional ao Tratado de Assunção sobre Meio Ambiente", documento apresentado ao GMC por meio da Recomendação 4/97 que, apesar de ter sido discutido em várias reuniões, não foi votado por sua má formulação. Severas críticas por parte de especialistas foram feitas por sua imprecisão na terminologia, carência de temas importantes e desordem na estruturação destes. Apesar de conter algumas improbidades técnicas, o projeto pode ser considerado audacioso ao fixar definições de dano ambiental, emergência ambiental e avaliação de impacto ambiental, abrangendo a área de Direito Ambiental (Idem).

No processo de discussão e elaboração do Protocolo houve uma maior mobilização tanto da sociedade civil do Uruguai como do Brasil, contando este com a participação de órgãos públicos como o Ministério Público de São Paulo, associações e fundações ambientalistas. Embora tenha havido resistência de outros países à adoção do Protocolo, o Brasil foi persistente em seu incentivo, o que levou a sucessivas reformulações do Protocolo Adicional e à proposição do Acordo-Quadro sobre o Meio Ambiente. 
O Acordo-Quadro sobre Meio Ambiente do Mercosul $^{1}$ foi um documento firmado pelo SGT-6, no qual reafirma os princípios constantes da Declaração do Rio de Janeiro sobre Meio Ambiente e Desenvolvimento, de 1992 (ECO 92), em que os países integrantes do bloco têm como objetivo "a proteção do meio ambiente e o desenvolvimento sustentável mediante a articulação entre as dimensões econômica, social e ambiental, contribuindo para uma melhor qualidade do meio ambiente e de vida das populações" (QUEIROZ, 2005). Este Acordo decorre do processo das negociações sobre a adoção de um Marco Jurídico necessário para o tratamento, dentro do bloco, das questões ambientais, que servisse de referência para os debates e ações dos países membros (IRACHANDE, 2002).

O Acordo-Quadro "é uma declaração de intenções", porém não obriga os estados a adotarem políticas ambientais específicas, nem mesmo a adotar, de forma clara, medidas de proteção a seus ecossistemas ou às zonas de fronteiras. Na verdade, o AcordoQuadro apresenta objetivos, instrumentos e compromissos que contribuem para a efetiva tutela ambiental por parte do Mercosul.

Para Viana (2004), embora o Acordo não tenha sido o ideal foi o passo inicial para os países do bloco econômico a aproximar suas legislações ambientais em nível da legislação brasileira, bem como a aprovação do Plano Geral de Cooperação e Coordenação Recíproca para a Segurança R. Na IV Reunião Extraordinária do SGT-6, ocorrida em Florianópolis, em 22 de junho de 2001, o Acordo-Quadro foi assinado, mediante a Decisão XX do Conselho do Mercado Comum.

Em 2000, no Brasil, foi realizada a XV Reunião Ordinária do SGT-6-Meio Ambiente, onde estiveram presentes as delegações da Argentina, Brasil, Paraguai e Uruguai, e do Chile na qualidade de observador, e representantes de setores privados. Na reunião, as delegações apresentaram considerações quanto à propositura do Acordo Marco de Cooperação em Matéria de Emergência no Mercosul, e a delegação brasileira mostrou a necessidade de vinculação

1 Na IV Reunião Extraordinária do SGT-6, ocorrida em Florianópolis, surgiu o Acordo-Quadro que foi assinado em 22 de junho de 2001, mediante a Decisão XX do Conselho do Mercado Comum. 
jurídica e institucional desse instrumento à proposta de Protocolo Adicional ao Tratado de Assunção sobre Meio Ambiente, elevada ao GMC na XI Reunião Ordinária, por meio da Rec/SGT no 6/ no 1/99, por ser este o marco jurídico.

Nessa ocasião, as delegações do Paraguai e Uruguai manifestaram que, tendo em vista a possibilidade de aprovação do Protocolo Adicional, eram favoráveis ao desenvolvimento dos aspectos operacionais do Acordo Marco, apesar da Argentina não considerar necessária a vinculação entre o Acordo e o Protocolo. No entanto, somente em 2004, o Decreto no 5.208, de 17/09/2004, promulgou o Acordo Quadro sobre Meio Ambiente do Mercosul, o que não ocorreu com o Protocolo Adicional, que não foi adotado até os dias atuais, embora devesse ter se tornado obrigatório em razão da sua importância.

\section{SGT-6: uma agenda perene e imutável}

Nas reuniões ordinárias e extraordinárias do SGT-6 pode-se verificar que há uma constância nos temas debatidos e pouco avanço em torno dos mesmos, se comparados aos avanços registrados em outras áreas de integração, como nas esferas econômica e comercial. Com relação às restrições comerciais não-tarifárias, que abrangem os produtos das áreas fauna e flora, recursos florestais, poluição do ar e resíduos tóxicos, as medidas restritivas foram justificadas e os procedimentos harmonizados, embora com discussões marcadas por posições bastante diversas entre os países membros (IRACHANDE, 2002).

No entanto, em razão da criação de novas legislações ambientais de cada país, o tema continuará sendo prioritário dentro da pauta ambiental do Mercosul. O Brasil detém o maior número de medidas restritivas ao comércio com base ambiental. $\mathrm{O}$ tema Emergências Ambientais tem se destacado como fundamental no SGT-6 por provocar efeitos degradadores ao meio ambiente, como as queimadas e enchentes. A Resolução GMC/RES/7/1998 abrange um compromisso genérico, e a realização das ações previstas nesse documento não se fizeram sentir. 
Em reunião realizada em agosto de 1996, o SGT 6-MA criou um grupo ad-hoc, responsável pelo Sistema de Informação Ambiental do Mercosul (SIAM). Os estados-parte foram instados a ter seu próprio sistema de informação ambiental. No Brasil, desde 1984, havia o Sistema Nacional de Informação do Meio Ambiente (SINIMA), alterado pelo Decreto no 3.942/2001, sob a responsabilidade do Ministério do Meio Ambiente.

Quanto ao tema Competitividade e Meio Ambiente, que trata de avaliação e estudos dos processos produtivos que assegurem condições equânimes de proteção ambiental e de competitividade entre os membros do bloco, outros países e agrupamentos regionais, inclusive quanto ao custo ambiental no processo produtivo, o acesso ao comércio mundial pelos países em desenvolvimento está relacionado à busca pelo Desenvolvimento Sustentável com a adoção de práticas e tecnologias que garantam a proteção ambiental, ou seja, melhor gerenciamento dos processos produtivos e do uso das matérias-primas, insumos, água e energia e a consequente redução de emissões.

Insere-se neste contexto o Projeto Competitividade e Meio Ambiente - Fomento da Gestão Ambiental e Produção Mais Limpa em Pequenas e Médias Empresas, por meio da cooperação técnica entre a República Federativa da Alemanha e o Mercosul (LEMOS, CASTRO \& CASTRO, 2003. Outro tema prioritário são as Normas Internacionais ISO ${ }^{2} 14000$, que correspondem ao segmento das normas internacionais de qualidade ambiental que permitem a entrada de produtos do bloco nos países desenvolvidos, e a comparação de produtos de diferentes países. Sua importância está em permitir identificar produtos nocivos ao ambiente durante a produção e substituí-los por outros ambientalmente neutros. Desde a introdução da ISO 14001, em 1996, as organizações têm buscado, voluntariamente, seguir seus requisitos. No mundo

2 ISO (International Standard Organization) - Sigla da organização internacional que estabelece padrões de medidas e qualidade para várias áreas. Para o Meio Ambiente e atividades relacionadas a ele foi lançada a série 14000 que estabeleceram critérios de classificação, verificação, padronização de avaliação e certificação. 
todo, em 2006, existiam 90.569 organizações certificadas, sendo que, no Brasil, somente com a marca INMETRO totalizavam 638 (AVILA \& PAIVA, 2006).

Outro tema relevante é o Selo Verde que está relacionado aos trabalhos da ISO sobre sistemas de certificação ambiental voluntária ou complementar, e ainda mais rigorosa que a adotada por aquela instituição. No âmbito do SGT-6 discute-se a adoção de Selos Verdes para pequenas e médias empresas. Segundo o Conselho Brasileiro de Manejo Florestal (FSC Brasil) ${ }^{3}$, o Selo Verde - o certificado que assegura a utilização de sistemas de exploração sustentável de florestas - não chega a ser uma novidade, e atinge um número pequeno de propriedades, ou seja, apenas 3,57 milhões de hectares de florestas brasileiras tinham conquistado o certificado em 2005, conforme dados do Conselho Brasileiro de Manejo Florestal.

Apesar da área de florestas certificadas ter evoluído muito, pois cresceu $147 \%$ em dois anos, ainda é pequena. Até 2005, o FSC tinha concedido o selo para 68 florestas e 188 cadeias de custódia, colocando o país na liderança mundial em número de certificações onde há rastreabilidade da matéria-prima. Também o Cerflor, programa nacional desenvolvido pelo Inmetro, é outra possibilidade para as empresas brasileiras demonstrarem seu compromisso com a conservação dos recursos naturais, mas o Selo Verde é usado em várias situações, inclusive o governo pensa em introduzir no Plano de Aceleração do Crescimento (PAC) na reforma da Lei no 8.666, que rege as licitações públicas, o conceito de licitações "verdes" como critério decisivo na seleção de propostas nas licitações públicas ${ }^{4}$.

3 AFCS Brasil - Conselho Brasileiro de Manejo Florestal foi concebida em 1996, é uma associação civil brasileira formada por representantes de organizações dos setores sociais, ambientais e econômicas. "O FSC é hoje o selo verde mais reconhecido em todo o mundo, com presença em mais de 75 países e todos os continentes. Em 2008, por exemplo, os negócios com produtos certificados geravam transações na ordem de 5 bilhões de dólares por ano em todo o globo. FSC é uma sigla em inglês para a palavra Forest Stewardship Council, ou Conselho de Manejo Florestal, em português". Disponível em: www.wwf.org.br.

4 Matéria: "Governo estuda utilizar critérios "verdes" nas compras de toda administração pública” disponível em: http://www.responsabilidadesocial.com/ article/article_view.php?id $=468$. 


\section{Considerações finais}

O aprofundamento da globalização econômica e da crescente interdependência entre as nações passou a exigir que os países da América Latina se unissem para enfrentar os desafios de um mundo que se internacionaliza dia-a-dia. Neste contexto, o Mercado Comum do Sul (Mercosul) surgiu da constatação de que com a ampliação dos mercados nacionais, por meio de sua integração, seria possível acelerar os processos de desenvolvimento econômico. (ROCHA et al., 2005).

O Mercosul, tendo o eixo econômico como orientação primordial, a construção de políticas comuns é dominada por este viés de busca da inserção dos países do bloco nos mercados internacionais. Quanto às políticas setoriais de outros segmentos, muitas são colocadas em segundo plano ou são negligenciadas, pois as questões de competitividade comercial estão em destaque. Com isso, tem-se a impressão de que o Mercosul é uma integração parcial, que está sempre sendo ameaçada por problemas que exigem um tratamento adequado, além dos diretamente ligados ao desenvolvimento comercial. (IRACHANDE, 2002)

No entanto, o Mercosul não se esgota em um projeto econômico, comercial. Conforme o preâmbulo do tratado constitutivo, estão contemplados, entre outros propósitos, a necessidade de maior "justiça social" e a preservação do meio ambiente, procurando "o mais eficaz aproveitamento dos recursos disponíveis, a preservação do meio ambiente e o melhoria das interconexões físicas" (inciso $2^{\circ}$ do preâmbulo) (MONTE BLANCO \& LINK, 2001 apud ROCHA et al., 2005)

O Tratado de Assunção - firmado entre Argentina, Brasil, Paraguai e Uruguai, em 26 de março de 1991 -, documento constitutivo do bloco de integração do Mercosul, faz alusão à questão ambiental, mas não está claramente contemplada ou diretamente referida. Os objetivos desse Tratado tratam essencialmente da inserção mais competitiva dos países membros num mundo em que se busca a consolidação de grandes espaços econômicos e em que a necessidade do progresso técnico se faz essencial.

As preocupações com os principais problemas ambientais presentes nos países do Mercosul como a hiperurbanização, a poluição 
industrial e agrícola, a degradação do solo, o desmatamento e a perda de biodiversidade, ocasionaram a criação das Reuniões Especializadas em Meio Ambiente (REMA) que ocorreram no período de novembro de 1993 a setembro de 1994. Em uma dessas reuniões foi recomendada a criação do Subgrupo de Trabalho do Meio Ambiente (SGT 6), que se efetivou em 1995, após a Primeira Reunião dos Ministros de Meio Ambiente dos países do Mercosul, em Montevidéu.

Apesar de várias reuniões, os resultados ambientais da REMA não passaram de intenções como a formulação de recomendações que assegurassem uma adequada proteção do meio ambiente no marco do processo de integração regional. A agenda do SGT6, que se reúne em forma ordinária trimestralmente, aborda os assuntos relativos às restrições não-tarifárias, competitividade e meio ambiente, normas internacionais (ISO 14.000), sistema de informações ambientais, emergências ambientais, Selo Verde Mercosul (desenvolvimento e formalização de um sistema de certificação ambiental comum) e relações com outros blocos.

Os grandes avanços no Mercosul foram a criação, em 2006, do Fundo para a Convergência Estrutural do Mercosul (Focem), que tem o objetivo de financiar programas que promovam a convergência do bloco e desenvolvam a competitividade, especialmente das economias menores e das regiões menos desenvolvidas do Mercosul, cujo primeiro projeto a ser desenvolvido será a erradicação da febre aftosa nos países que integram o bloco ${ }^{5}$ e a constituição

5 Os recursos do Focem virão de contribuições anuais dos países integrantes do Mercosul. Foi acertado que o valor anual do fundo será de 100 milhões de dólares (aproximadamente R\$ 216 milhões). O Brasil deverá contribuir com 70\% desse valor, que, de acordo com a regra de transição, será atingido apenas no terceiro ano orçamentário de funcionamento do fundo. No primeiro e no segundo ano, os recursos do Focem serão equivalentes a $50 \%$ e a $75 \%$, respectivamente, do total definitivo. Dessa forma, o Brasil deverá depositar inicialmente 35 milhões de dólares (cerca de R\$ 75,6 milhões). Pela proposta, a Argentina será responsável por $27 \%$ das contribuições dos países do bloco ao fundo; o Uruguai, por $2 \%$; e o Paraguai, por $1 \%$. Esses percentuais foram definidos com base na média histórica do Produto Interno Bruto (PIB) do Mercosul. O Focem também poderá receber contribuições de outros países, de instituições ou de organismos internacionais para o desenvolvimento de projetos. A distribuição dos recursos será inversamente proporcional à contribuição: $48 \%$ para os projetos apresentados pelo Paraguai; $32 \%$ para os do Uruguai; $10 \%$ para os da Argentina; e 10\% para 
do Parlamento do Mercosul ${ }^{6}$, tendo função consultiva e opinativa. Como órgão fiscalizador, deve aprovar a proposta das presidências e também suas prestações de contas e a criação de um fundo dos quatro países para remediar e enfrentar danos ambientais causados por situações emergenciais, como queimadas e enchentes que, muitas vezes, foram preocupações nas reuniões do SGT-6.

A questão da proteção ambiental e o uso sustentável dos recursos naturais se impõem como pontos centrais por sua própria natureza e dinâmica e, sobretudo, pelo apelo intrínseco representado pela ameaça imposta pela contínua degradação do ambiente para os indivíduos, particularmente para a espécie humana como um todo, ou ainda, para todas as formas de vida no planeta, segundo os tipos de degradação e consequiências. Algumas dessas ameaças são iminentes, outras a médio e longo prazos.

Nota-se que o debate sobre a questão ambiental está sendo incorporado progressivamente no processo decisório, porém ainda ocupa um lugar de menor destaque se comparado com as políticas setoriais de competitividade comercial e coordenação de políticas macroeconômicas. Assim, a integração equilibrada entre políticas comerciais e ambientais, observadas as evidências empíricas, tem se demonstrado como condição primordial para assegurar a construção de um modelo de desenvolvimento fundamentado na sustentabilidade.

Algumas ações devem ser consideradas no âmbito do Mercosul voltadas para a sustentabilidade do meio ambiente. São elas:

1 - Estabelecer procedimento administrativo de preservação do dano ambiental nacional transfronteiriço. Não há nesse bloco normas que estabelecem um Estudo de Impacto Ambiental de danos nacionais trans-fronteiriços.

os do Brasil. Maiores informações leia a matéria Fundo busca desenvolver infra-estrutura no Mercosul no endereço http:/www2.camara.gov.br/internet/ homeagencia/materias.html?pk=96417. Consulta feita em 18-11-07

6 A instalação do Parlamento do Mercosul atende à decisão do Conselho Mercado Comum (49/04) e também ao protocolo constitutivo firmado pelos chefes de Estado dos países integrantes, em dezembro de 2005, em Montevidéu, que determinou a sua constituição até 31 de dezembro de 2006. 
2 - Proporcionar solução de controvérsias ambientais e acesso à Justiça no Mercosul. O Acordo-Quadro sobre Meio-Ambiente do Mercosul, embora haja sido promulgado pelo Decreto n $\mathrm{o}$ 5.208 , de 17 de setembro de 2004, não foi ratificado por todos os estados-partes, o que implica concluir que os sistemas de solução de controvérsias do Mercosul ainda não podem exercer suas atividades em casos de conflitos a respeito de questões ambientais.

3 - Favorecer o acesso aos Poderes Judiciários nacionais - a garantia da igualdade de acesso aos cidadãos nacionais e estrangeiros ao judiciário dos países do Mercosul, ou de um tribunal comunitário criado para defesa do direito de viver em um ambiente sadio e equilibrado. Isto porque no plano do Direito Internacional atual, não existe norma estruturante da igualdade de acesso às jurisdições entre nacionais e estrangeiros para a solução de problemas ambientais.

4 - A criação de uma agenda verde comum, que promova uma discussão quanto às questões ambientais que assolam os países que participam do Mercosul, para que ações proativas efetivas possam ser tomadas, bem como que se institua um fórum de discussão ad eternum.

Finalmente, pode-se constatar que as grandes dificuldades em se construir políticas setoriais comuns e instrumentos conjuntos para uma atuação efetiva do Mercosul são reflexo direto das assimetrias existentes entre os integrantes do grupo, agravadas pelas vulnerabilidades externas que os países-membros do bloco apresentam. O baixo peso político e operacional que os poucos fóruns de debates sobre questões ambientais apresentam e a organização político-institucional do próprio bloco de integração, ilustram sobremaneira a marginalização do tema dentro da área de integração. A consequência mais direta desta constatação é a ausência de uma agenda clara e aplicável que sirva de norte para a gestão ambiental coletiva no âmbito do Mercosul. 


\section{Bibliografia}

AVILA, G.J.; PAIVA, E.L. Processos Operacionais e Resultados de Empresas Brasileiras após a Certificação Ambiental ISO 14001. 2006. Disponível em: http://www.scielo.br/pdf/gp/v13n3/09.pdf.. Consulta em 23-10-2007.

CAMPOS, M.O. Direito Ambiental Internacional no Mercosul. Recanto das Letras. Disponível em http://recantodasletras.uol.com. br/textosjuridicos/738402. Consulta em 18-11-07.

ENGELMANN, B.M. Os desafios constitucionais do processo de integração regional. Jus Navigandi, Teresina, ano 11, n. 1537, 2007. Disponível em: http://jus2.uol.com.br/doutrina/texto.asp?id=10398. Consulta em 16-11-2007.

IRACHANDE, A.M. O Mercosul e a Política Ambiental: uma Integração sem Agenda Verde. Tese de Doutorado. Universidade de Brasília. Centro de Desenvolvimento Sustentável. Brasília, 2002.

LEMOS, H.M.; CASTRO \& CASTRO, M.I. Competitividade e Meio Ambiente no Mercosul. Relatório baseado nas 4 recopilações nacionais realizadas no marco do projeto Mercosul - GTZ. 2003.

LOPES, F.A.M.Y. \& BELINCANTA, F.C. Estudo da Evolução do Tratamento Ambiental no Mercosul: do Tratado de Assunção até o Acordo-Quadro sobre Meio Ambiente, 2002. Disponível em: http://jus2.uol.com.br/ doutrina/texto.asp?id=3305. Consulta em 11-11-2007.

QUEIROZ, F. Meio Ambiente e Comércio na Agenda Internacional: a questão ambiental nas negociações da OMC e dos Blocos Econômicos Regionais. Ambiente \& Sociedade, vol.8, n. 2. Campinas, 2005.

RIBEIRO, Cynthia. Ministério do Meio Ambiente. Selo Verde. Disponível em: www.responsabilidadesocial.com. Consulta em 22-10-07.

ROCHA, E.C. et al. Avaliação de Impactos Ambientais nos Países do Mercosul. Ambiente \& Sociedade - Vol. 8, noㅜ. 2. Campinas, 2005.

SOUZA, P.R.P. Harmonização de Leis Ambientais em 10 anos de Mercosul. Disponível em: http:/www.oab.org.br/comissoes/coda/ files/artigos/\%7BAA15B305-F99D-43B6-9763-E9C4E1613EC9\%7D_ leisambientaisMercosul.pdf. Consulta em 22-10-2007. 
STJ. O Poder Judiciário no Novo Milênio e as Questões do Mercosul. Disponível em: http://bdjur.stj.gov.br/dspace/bitstream/2011/277/1/O_ Poder_Judici\%C3\%A1rio_no_Mil\%C3\%AAnio.pdf. Consulta em 23-10-2007.

SUPES - Superintendência do IBAMA no Distrito Federal. Proconve alcança redução de $98 \%$ na emissão de carbono dos veículos. Matéria publicada em 09-08-06. Disponível em: http://www.ibama.gov.br/df/ index.php?id_menu=97\&id_arq $=48$. Consulta em 22-10-2007.

VIANA, M.B. O Meio Ambiente no Mercosul. Câmara Legislativa, maio de 2004. Disponível em: http://www2.camara.gov.br/internet/ publicacoes/estnottec/tema14/pdf/2004_2023.pdf. Consulta em 23-10-2007.

\section{Abstract \\ Mercosul and the construction of environmental policy for Sou- thern Cone countries}

From 1991, when Argentina, Brazil, Paraguay and Uruguay agreed to create the Mercosur, until now, a relative advance occurred in the process of commercial integration of these countries. However, a small progress has been verified in this forum of discussion in what concerns the environmental questions. This article aims to analyze the way that the environmental question is been managed in the various institutionalized legal instruments of Mercosur, showing the different attempts to adopt steps with a view to harmonize the environmental legislation, as well as the reasons for the establishment of a common policy of environmental protection within the process of regional integration, without this entailing the unification of the environmental policies of the different country members of Mercosur.

Keywords: Asunción Treaty, Mercosur, Environmental Question, Commercial Integration, Ouro Preto Protocol. 
